
\title{
28 Research Square \\ In vitro effect of codeine on human sperm motility and DNA integrity
}

Roland Eghoghosoa Akhigbe

Ladoke Akintola University of Technology

Moses Agbomhere Hamed

Buntai Laboratory

Lydia Oluwatoyin Ajayi

Adeleke University

Davinson Chuka Anyogu

University of Nigeria

Ayodeji Folorunsho Ajayi ( $\sim$ jy_ayodeji@yahoo.com )

Ladoke Akintola University of Technology

\section{Research Article}

Keywords: sperm, integrity, codeine, membrane, motility, plasma

Posted Date: August 11th, 2021

DOl: https://doi.org/10.21203/rs.3.rs-786839/v1

License: (c) (1) This work is licensed under a Creative Commons Attribution 4.0 International License.

Read Full License 


\section{Abstract \\ Purpose}

This study assessed the in vitro effect of codeine, a popular drug of abuse, on human spermatozoa motility, plasma membrane integrity, DNA integrity, and oxidative stress.

\section{Materials and Methods}

Semen samples were collected from fifteen healthy donors and conventional semen analysis was carried out per the guideline of the World Health Organization. Direct Swim-up technique was performed to obtain highly motile sperm. Samples were incubated at $34.5^{\circ} \mathrm{C}$ with different concentrations $(0,0.1,1,5$ and $10 \mathrm{mM})$ of codeine. The non-exposed $(0 \mathrm{mM})$ was used as the control group. Sperm motility and DNA integrity were assessed at 30,60, and 90 minutes, while sperm membrane integrity and sperm 8OHdG level were determined at 90 minutes.

\section{Results}

Codeine at any tested concentration significantly reduced sperm motility and plasma membrane integrity but increased sperm 8-OHdG level compared to the control in a time-dependent manner. Furthermore, codeine at 1, 5, and $10 \mathrm{mM}$ markedly increased sperm DNA damage. In addition, correlation study showed that sperm $80 \mathrm{HdG}$ level was negatively associated with sperm motility, plasma membrane integrity, and DNA integrity.

\section{Conclusions}

Codeine may impair human spermatozoa fertilization capacity by inducing sperm dysmotility and damage to the sperm plasma membrane and DNA through an oxidative stress-dependent mechanism.

\section{Introduction}

There is a global rise in the abuse of opioids [1-3]. Among the opioids that are commonly abused is codeine [4], which seems to be the most abused opioid after cannabis [4-6]. Although its therapeutic use as an analgesic and antitussive is uncontroversial, the development of tolerance within a short period of use results to its abuse and addiction [7]. It is toxic to cardiorenal tissue [8], liver [9], and neuronal cells [10-12]. Codeine has also been found to impair male reproductive function through suppression of circulatory androgen [13] and oxidative testicular and sperm damage [14-17]. Safarinejad and his colleagues [18] demonstrated that opiate consumption adversely affects semen quality and sperm DNA among opioids addicts via an oxidative-stress mediated pathway, although their study failed to examine 
and control for multiple opioids interactions as many of the studied participants took different types of opiates. Hence, data reporting the impact of codeine on human spermatozoa is still lacking.

Although the conventional semen analysis remains the cornerstone for diagnosing male infertility [19], advanced semen studies provide useful details on sperm DNA integrity $[19,20]$ and detect subtle sperm defects that could be missed by the conventional assay [20]. Sperm motility is a prerequisite for sperm function, including oocyte fertilization. For fertilization to occur, the spermatozoa undergo capacitation, which is a period of conditioning in the female reproductive tract at which time a glycoprotein and seminal plasma proteins are shed from the sperm plasma membrane overlying the acrosomal region [21]. The capacitated spermatozoa undergo acrosome reaction, which involves the digestion of the zona pellucida by acrosin (serine proteases) [21]. These processes require optimal sperm motility. Hence, exposure to molecules capable of inducing dysmotility might impair the fertilizing capacity of the sperm cells. On the other hand, intact sperm DNA is important for oocyte fertilization and transmission of DNA without defects. The sperm DNA organization allows the tightly packed genetic materials to be transferred to the oocyte and ensures that the DNA is delivered in a physiological form that permits the developing embryo to easily access the genetic materials [20]. Thus, damage to the sperm DNA impairs fertilization process and the transmission of genetic materials to the embryo.

Oxidative stress has been implicated in many disorders [22, 23] including male infertility [15, 24].

Spermatozoa are prone to oxidative stress, as they have a high level of polyunsaturated fatty acids in the membrane [25]. In addition, sperm cells release most of the antioxidant enzymes-containing cytoplasm during spermiogenesis [24]. These make them susceptible to lipid peroxidation with negative impacts on sperm motility [26] and sperm DNA integrity [24]. Common aetiological factors of oxidative stress in spermatozoa include leukocytes [27], increased scrotal temperature [28], and exposure to toxicants/drugs $[1,28]$.

Despite the wide abuse of codeine and the growing incidence of male infertility, the effect of codeine on human spermatozoa is yet to be explored. Although previous experimental studies in laboratory animals demonstrated that codeine induces sperm dysmotility, suppression of testosterone, and poor fertility indices [13-17], whether or not a similar effect is exerted by codeine on human spermatozoa remains unclear. This study was thus designed to evaluate the in vitro effects of codeine in graded concentrations and exposure durations on sperm motility, viability, and DNA integrity in normozoospermic semen samples from healthy non-abusers of substances.

\section{Materials And Methods}

Chemical

The National Drug Law Enforcement Agency (NDLEA) kindly donated the codeine used for research purposes only. ELISA kit for 8-hydroxy-2'-deoxyguanosine (8OHdG) was obtained from Elabscience Biotechnology Co., Ltd, USA. 
The study protocol was approved by our Institutional Review Board. Semen samples were collected from fifteen healthy male volunteers after obtaining informed consents, and analyzed per the 5 th edition of the World Health Organization (WHO) manual for the examination of human semen [29]. Semen samples were obtained after 2-7 days of ejaculatory abstinence, allowed to liquefy at room temperature for 15 minutes and an aliquot was taken from each sample for semen analysis. Only semen samples with adequate functional parameters as defined by WHO were used for the study (sperm volume: 1.4-1.7 ml; sperm concentration: $12-16 \times 10^{6} / \mathrm{ml}$; total sperm number: $33-46 \times 10^{6} /$ ejaculate; total motility: $38-42 \%$; progressive motility: 31-34\%). Motile sperm fractions were obtained from the semen samples by the Direct Swim-up technique using Biggers-Whitten- Whittingham (BWW) capacitation medium supplemented with $3 \%$ Bovine Serum Albumin. The obtained semen samples containing highly motile sperm cells were divided into equal aliquots.

Semen samples were exposed to different concentrations of codeine $(0,0.1,1,5$, and $10 \mathrm{mM})$. Samples were incubated at $34.5^{\circ} \mathrm{C}$ (physiological temperature of testes) for different time intervals. Sperm motility and DNA integrity (using Toluidine blue) were assessed at 30, 60, and 90 minutes, while sperm plasma membrane integrity (using the hypo-osmotic swelling test, HOST) and sperm 8-OHdG level were determined at 90 minutes.

Assessment of sperm motility

After mixing the semen sample properly, an aliquot was immediately taken and used for a wet preparation on a clean slide. Approximately, 200 spermatozoa were assessed on the slide at $x 200$ and x400 magnification for progressive motility and scored. Each slide was scored by two different experts, and the mean of their values was taken as the percentage progressive motility [15, 29].

Assessment of sperm membrane integrity

The sperm plasma membrane integrity was determined using the HOST [15, 29]. Briefly, $100 \mu$ l aliquot was taken from the well-mixed semen sample and added to $1000 \mu \mathrm{l}$ of the hypo-osmotic solution (containing $0.735 \mathrm{~g}$ of sodium citrate dehydrate and $1.351 \mathrm{~g}$ of fructose in $100 \mathrm{ml}$ of distilled water), then mixed gently. The suspension was incubated at $37^{\circ} \mathrm{C}$ for 30 minutes. Then a $10-\mu l$ aliquot was transferred from the suspension to a clean slide and covered with a coverslip. Approximately, 200 spermatozoa were examined on the slide at $\mathrm{x} 200$ and x400 magnification for sperm tail swelling. Vital spermatozoa (with intact plasma membrane integrity) have swollen tails, while dead spermatozoa (without intact plasma membrane integrity) have unswollen tails. Each slide was scored by two different experts, and the mean of their values was taken as the percentage of spermatozoa with intact plasma membrane integrity.

Assessment of sperm DNA integrity 
Sperm DNA integrity was assessed using the Toluidine blue staining as previously reported $[25,30]$. An aliquot of the semen sample was taken for smear preparation and allowed to dry. The dried smear was fixed with freshly prepared $96 \%$ ethanol: acetone $(1: 1)$ at $4^{\circ} \mathrm{C}$ for 30 minutes and air-dried. The smear was then hydrolyzed with $0.1 \mathrm{~N} \mathrm{HCl}$ at $4^{\circ} \mathrm{C}$ for 5 minutes and rinsed in distilled water for 2 minutes. The rinsing was done three times. After rinsing, toluidine blue was applied to the slide and allowed to dry at room temperature for 5 minutes. Approximately, 200 spermatozoa were examined per slide at x1000 magnification. Spermatozoa with intact DNA had sperm heads stained light blue or blue while those with damaged DNA had sperm heads stained dark blue or purple.

Assessment of sperm 8-OHdG level

Sperm $80 \mathrm{HdG}$ level was determined based on the Competitive-ELISA principle using a standard ELISA kit per manufacturer's guidelines.

Statistical analysis

Data were analyzed using Statistical Package for Social Sciences (SPSS, version 16). One-way analysis of variance (ANOVA) followed by Tukey's posthoc test for pair-wise comparison was carried out to determine the significant difference across the groups. Pearson's bivariate correlation was done to assess the association between 8-OHdG and sperm motility, membrane integrity, and DNA integrity. Data are presented as means (SD). $P$ values $<0.05$ were considered statistically significant.

\section{Results}

Motility

Codeine led to a significant reduction in sperm motility compared to the control (Fig. 1). The degree of change in sperm motility was dependent on the codeine concentration and incubation time. Codeine at $10 \mathrm{mM}$ exerted the most prominent effect. Similarly, increasing incubation time caused a further reduction in sperm motility.

Sperm plasma membrane integrity

Sperm plasma membrane integrity, evaluated by HOST, was significantly reduced by codeine compared to the control (Fig. 2). The impact of codeine on sperm plasma membrane integrity was noted to be dosedependent.

Sperm DNA integrity

Sperm DNA integrity was significantly reduced by codeine at 1, 5, and $10 \mathrm{mM}$ throughout the exposure period compared to the control. The $0.1 \mathrm{mM}$ codeine exposure group had comparable sperm DNA integrity with the control throughout the incubation period (Fig. 3 and 4). 
There was a significant increase in sperm level of 8-OHdG, a marker of oxidative DNA injury, after 90 minutes of incubation with codeine compared to the control. The observed oxidative sperm DNA damage was also dose-dependent (Fig. 5).

\section{Correlation study}

Correlation analysis revealed that oxidative sperm DNA damage was negatively associated with sperm motility, sperm plasma membrane integrity, and sperm DNA integrity (Fig. 6). The association was highest for sperm motility followed by sperm plasma membrane integrity.

\section{Discussion}

The goal of the current study was to evaluate the impact of codeine on human spermatozoa using an in vitro model. It was observed that codeine treatments caused a dose-dependent impairment on the physiological function and structural integrity of human spermatozoa. Codeine exposure caused a marked reduction in human sperm motility, sperm membrane integrity, and sperm DNA integrity. This was accompanied by a marked rise in sperm 8-OHdG level. Furthermore, it was observed that human sperm 8OHdG was negatively correlated with sperm motility, sperm plasma membrane integrity, and sperm DNA integrity (Figure 7).

The present finding that codeine significantly reduced sperm motility is in consonance with our earlier report in rats following oral codeine exposure [15]. This also agrees with previous findings that demonstrated that morphine, the active metabolite of codeine, caused a significant reduction in sperm motility [31,32]. The impact of codeine on unwashed semen samples would likely be similar or even worse than that observed in washed semen samples in this study as the unwashed semen would contain a higher concentration of reactive oxygen species (ROS). Hence, it could be inferred that codeine may impair sperm capacitation, acrosome reaction, and oocyte fertilization by reducing sperm motility, a prerequisite for sperm function [21].

Results of the current study clearly showed that in vitro codeine exposure was able to reduce human sperm plasma membrane integrity and DNA integrity. Although, at $0.1 \mathrm{mM}$, codeine led to marginal sperm DNA damage which was yet statistically comparable to that of the control group; exposures to 1, 5, and $10 \mathrm{mM}$ of codeine induced a greater degree of sperm DNA damage. This agrees with earlier findings from our laboratory that showed that oral codeine exposure for 6 weeks induced both sperm plasma membrane and sperm DNA damage [15]. The current in vitro study may be representative of the in vivo effect of codeine abuse in humans. It is thus plausible to construe that codeine has the potential to impair oocyte fertilization and transmission of DNA to the embryo since intact sperm DNA is key for fertilization process and transmission of DNA without defects [20].

Codeine-induced alteration in sperm motility, plasma membrane, and DNA was accompanied by a significant rise in sperm 8-OHdG level. This finding corroborates our previous findings in laboratory animals that suggest that codeine-induced sperm DNA damage is primarily via oxidative stress [15]. This 
could imply that codeine promotes ROS production not just by impairing the nicotinamide adenine dinucleotide phosphate oxidase system at the level of the sperm plasma membrane, but also by distorting the nicotinamide adenine dinucleotide-dependent oxido-reductase reaction at the mitochondrial level, the two main sources of sperm ROS [32]. This results in mitochondrial dysfunction and ATP/energy depletion, which is needed for sperm motility [34]. It is worthy to note that codeine, at $0.1 \mathrm{mM}$, induced oxidative DNA damage with a physiological outcome (dysmotility), it was likely not sufficient to cause structural damage (DNA integrity). However, at 1, 5, and $10 \mathrm{mM}$, codeine sufficiently triggered ROS-driven oxidative DNA injury to the human spermatozoa with consequent dysmotility and impaired DNA integrity. At physiological levels (low and controlled concentrations), ROS play essential roles in capacitation, hyperactivation, acrosome reaction, and sperm-oocyte fusion, thus promoting fertilization, at high concentrations, ROS trigger oxidative damage to the spermatozoa [35]. The present findings demonstrate that codeine enhances excessive ROS release.

In conclusion, our present study provides compelling pieces of evidence that high levels of codeine exposure might reduce human spermatozoa fertilization capacity by decreasing motility and inducing sperm plasma membrane and DNA damage via an oxidative stress-dependent mechanism.

\section{Declarations}

\section{Acknowledgements}

Authors are grateful to Buntai Medical and Diagnostic Laboratories, Nigeria and Reproductive Biology and Toxicology Research Laboratories, Oasis of Grace Hospital, Nigeria for providing facilities and funds for this study.

\section{Author Declaration}

\section{Competing interest}

The authors declare that there are no competing interests.

\section{Ethics approval}

The study was approved by the Ethics Review Committee of Oasis of Grace Hospital, Osogbo, Nigeria (OG/2020/077).

\section{Consent to participate}

Consent was obtained from volunteer donors of semen samples.

\section{Consent to publish}

All authors agree to the publication of this article. 
Availability of data and material

Data and materials are available upon request from the corresponding author.

\section{Code availability}

$\mathrm{N} / \mathrm{A}$

\section{Authors' contributions}

Conceptualization and study design: ARE and AAF

Experimentation: ARE, ALO, ADC, AAF

Contribution of reagents: ARE, ALO, ADC, AAF

Statistical analysis: ARE, ALO

Writing of first draft: ARE

Revision of the first draft: All authors

Approval for submission and publication: All authors

\section{References}

1. Ajayi AF, Akhigbe RE. The physiology of male reproduction: Impact of drugs and their abuse on male fertility. Andrologia. 2020;00:e13672. https://doi.org/10.1111/and.13672.

2. NSDUH. 2016 National Survey on Drug Use and Health, Rockville, MD. Substance Abuse and Mental Health Services Administration, 2017.

3. Fischer B, Rehm J. Revisiting the 'paradigm shift' in opioid use: Developments and implications ten years later. Drug Alcohol Rev 32018; 7: S199-S202.

4. INCB. International Narcotics Control Board. Narcotic drugs estimated world requirements for 2012. Vienna, 2012.

5. Bakare AT, Isah BA. Psychoactive substances use among inpatients in a Nigerian neuropsychiatric hospital: prevalence, pattern and presentation. MOJ Addict Med Ther. 2016;2:18-22.

6. Garba US, Sholey ZG, Maryam MB, Usama BU. A survey of the usage and users of codeine containing cough syrups in Maiduguri. Nigeria Adv Psychol Neurosci. 2017;2:42-6.

7. Sproule BA, Busto UE, Somer G, Romach MK, Sellers EM. Characteristics of dependent and nondependent regular users of codeine. J Clin Psychopharmacol. 1999;19:367-72.

8. Akhigbe RE, Ajayi LO, Ajayi AF. Codeine exerts cardiorenal injury via upregulation of adenine deaminase/xanthine oxidase and caspase 3 signaling. Life Sci. 2021;273:118717. https://doi.org/10.1016/j.Ifs.2020.118717. 
9. Akhigbe RE, Ajayi LO, Adelakun AA, Olorunnisola OS, Ajayi AF. Codeine induced hepatic injury is via oxido-inflammatory damage and caspase-3-mediated apoptosis. Mol Biol Rep. 2020;47(12):952130.

10. Ajayi AF, Akhigbe RE. Apoptotic inducement of neuronal cells by codeine: possible role of disrupted redox state and caspase 3 signaling. Heliyon. 2021;7:e07481. https://doi.org/10.1016/j.heliyon.2021.e07481.

11. Archibong VB. Ekanem T., Igiri A. Ofutet E.O., and Ifie J.E. The effect of codeine administration on oxidative stress biomarkers and the expression of the neuron-specific enolase in the brain of Wistar rats. Naunyn-Schmeideberg's Arch Pharmacol. 2021; 394: 1665-73. https://doi.org/10.1007/s00210-021-02094-2.

12. Achibong VB, Ekanem TB, Igiri AO, Lemuel AM, Usman IM, Okesina AA, Obosi NJ. Immunohistochemical studies of codeine medication on the prefrontal cortex and cerebellum of adult Wistar rats. Cogent Medicine. 2020;7(1):1824390. Doi:10.1080/2331205X.2020.1824390.

13. Ajayi AF, Akhigbe RE. Assessment of sexual behaviour and fertility indices in male rabbits following chronic codeine use. Andrology 2020; 8: 509-515. https://doi.org/10.1111/andr.12717 PMID: 31627249.

14. Akhigbe R, Ajayi A. Testicular toxicity following chronic codeine administration is via oxidative DNA damage and up-regulation of NO/TNF- $a$ and caspase 3 activities. PLoS ONE. 2020;15(3):e0224052. https://doi.org/10.1371/journal.pone.0224052.

15. Ajayi AF, Akhigbe RE. Codeine induced sperm DNA damage is mediated predominantly by oxidative stress rather than apoptosis. Redox Rep. 2020;25(1):33-40. DOI:10.1080/13510002.2020.1752003.

16. Ajayi AF, Akhigbe RE. In vivo exposure to codeine induces reproductive toxicity: role of HER 2 and p53/Bcl-2 signaling pathway. Heliyon. 2020;6:e05589. Doi:10.1016/j.heliyon.2020.e05589.

17. National Toxicology Program. NTP toxicology and carcinogenesis studies of codeine (CAS No. 7657-3) in F344 rats and B6C3F1 Mice (Feed studies). Natl Toxicol Program Tech Rep Ser Actions. 1996;455:1-275.

18. Safarinejad MR, Asgari SA, Farshi A, Ghaedi G, Kolahi AA, Iravani S, Khoshdel AR. The effects of opiate consumption on serum reproductive hormone levels, sperm parameters, seminal plasma antioxidant capacity and sperm DNA integrity. Reprod Toxicol. 2013;36:18-23.

19. Dutta S, Henkel R, Agarwal A. Comparative analysis of tests used to assess sperm chromatin integrity and DNA fragmentation. Andrologia. 2021;53(2):e13718.

20. Agarwal A, Allamaneni SSR. Sperm DNA damage assessment: a test whose time has come. Fertil Steril. 2005;84(4):850-3.

21. Yanagimachi R. Mammalian fertilization. In: Knobil E, Neill JD, editors. The Physiology of Reproduction. St Louis: Elsevier Academic Press; 1994. pp. 189-317.

22. Akhigbe R, Ajayi A. The impact of reactive oxygen species in the development of cardiometabolic disorders: a review. Lipids in Health Disease. 2021;20:23. Doi:10.1186/s12944-021-01435-7. 
23. Akhigbe RE, Hamed MA. Co-administration of HAART and antikoch triggers cardiometabolic dysfunction through an oxidative stress-mediated pathway. Lipids in Health Disease. 2021;20:62. Doi:10.1186/s12944-021-01493-x.

24. Aitken RJ, Curry BJ. Redox regulation of human sperm function: from the physiological control of sperm capacitation to the etiology of infertility and DNA damage in the germ line. Antioxid Redox Signal. 2011;14:367-81. doi:10.1089/ars.2010.3186.

25. Akhigbe RE, Hamed MA, Aremu AO. HAART exacerbates testicular damage and impaired spermatogenesis in anti-Koch-treated rats via dysregulation of lactate transport and glutathione content. Reprod Toxicol. 2021;103:96-107.

26. Cambi M, Tamburrino L, Marchiani S, Olivito B, Azzari C, Forti G, Baldi E, Muratori M. Development of a specific method to evaluate 8-hydroxy,2-deoxyguanosine in sperm nuclei: relationship with semen quality in a cohort of 94 subjects. Reproduction. 2013;145:227-35.

27. Cocuzza M, Sikka SC, Athayde KS, Agarwal A. Clinical relevance of oxidative stress and sperm chromatin damage in male infertility: an evidence based analysis. International Brazilian Journal of Urology. 2007;33:603-21. doi:10.1590/S1677-55382007000500002).

28. Lanzafame FM, La Vignera S, Vicari E, Calogero AE. Oxidative stress and medical antioxidant treatment in male infertility. Reproductive BioMedicine Online. 2009;19:638-59. doi:10.1016/j.rbmo.2009.09.014.

29. World Health Organization. WHO laboratory manual for the examination and processing of human semen. 5th ed. Geneva: World Health Organization; 2010.

30. Erenpreisa J, Erenpreiss J, Freivalds T, Slaidina M, Krampe R, Butikova J, Ivanov A, Pjanova D. Toluidine blue test for sperm DNA integrity and elaboration of image cytometry algorithm. Cytom Part A. 2003;52A:19-27.

31. Jalili C, Salahshoor MR, Jalili F. Therapeutic effect of resveratrol on morphine-induced damage in male reproductive system of mice by reducing nitric oxide serum level. Int JMorphol. 2017;35(4):1342-7.

32. Singer R, Ben-bassat M, Malik Z. Oligozoospermia. Asthenozoospermia, and sperm abnormalities in ex-addict to heroin, morphine, and hashish. Arch Androl. 1986;16(2):167-74.

33. Agarwal A, Virk G, Ong C, du Plessis SS. Effect of oxidative stress on male reproduction. World J Mens Health. 2014;32(1):1-17.

34. Henkel RR. Leukocytes and oxidative stress: dilemma for sperm function and male fertility. Asian J Androl. 2011;13:43-52.

35. Saleh RA, Agarwal A. Oxidative stress and male infertility: from research bench to clinical practice. J Androl. 2002;23:737-52.

\section{Figures}



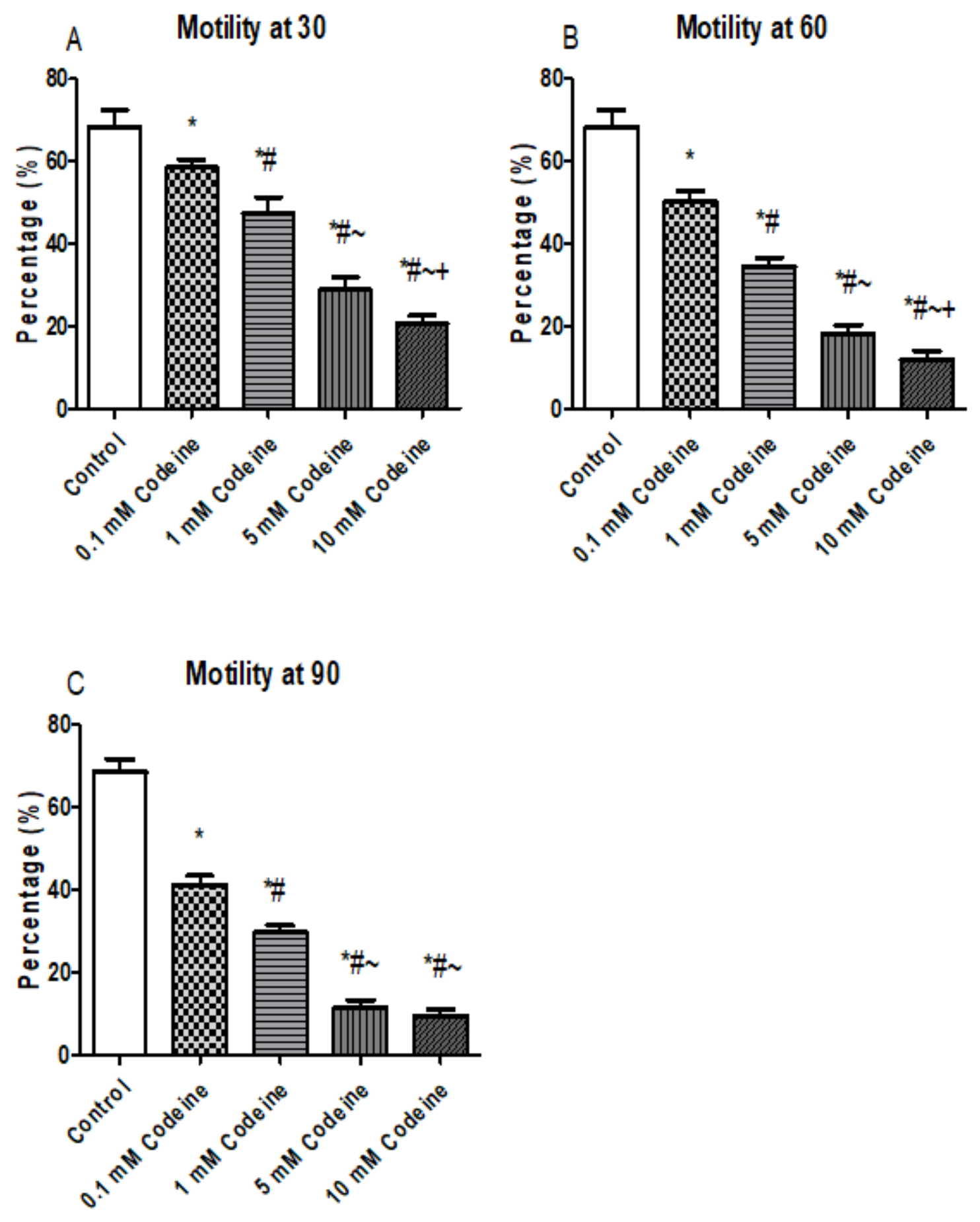

Figure 1

The effect of in vitro exposure to codeine on human sperm motility Data are presented as mean \pm SD of 5 replicates; *P < 0.05 vs control; \# P $<0.05$ vs $0.1 \mathrm{mM} ; ~ P<0.05$ vs $1 \mathrm{mM}, \sim \mathrm{P}<0.05$ vs $5 \mathrm{mM}$ 

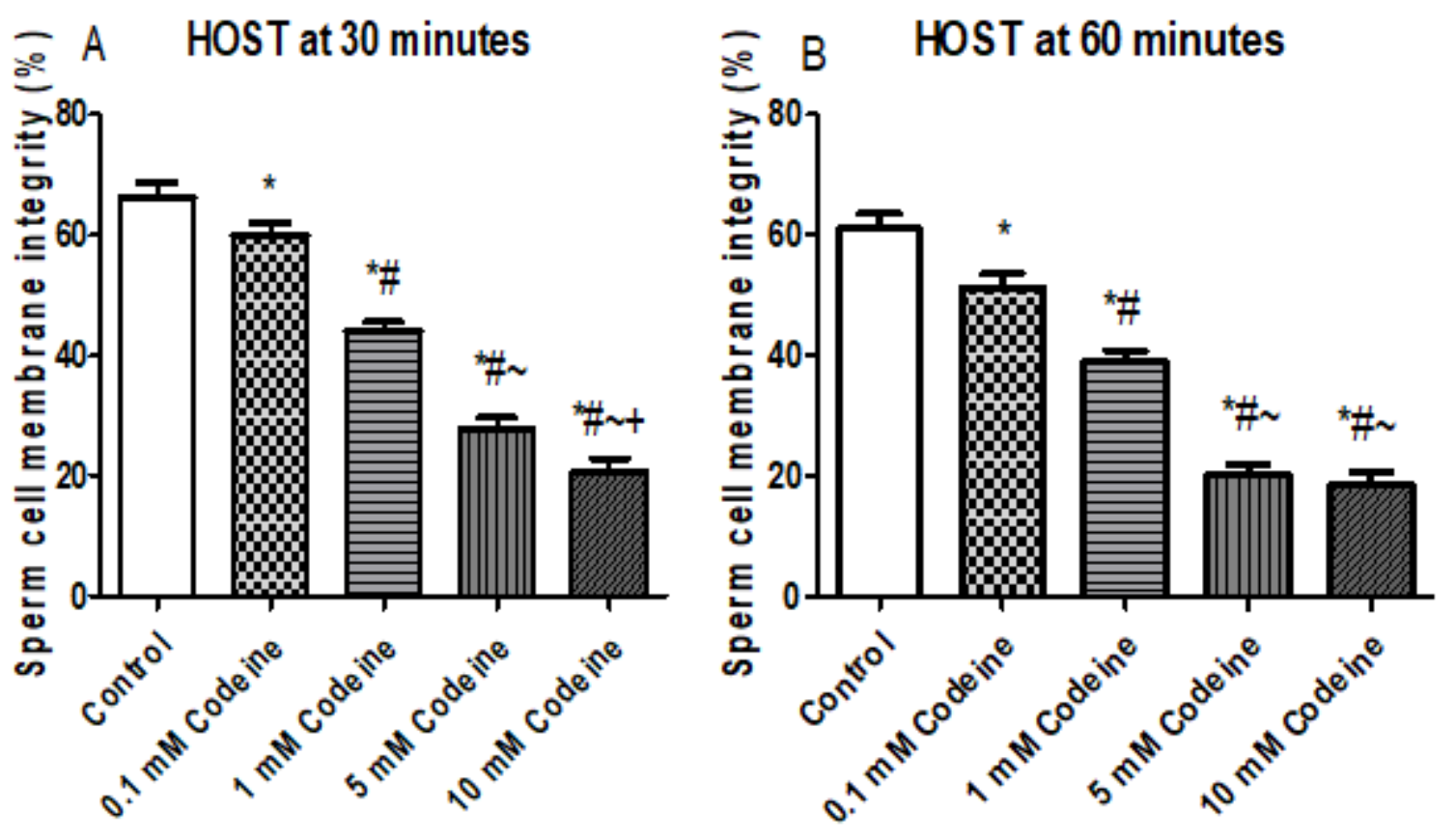

Figure 2

The effect of in vitro exposure to codeine on human sperm plasma membrane integrity using the hypoosmotic swelling test (HOST) Data are presented as mean \pm SD of 5 replicates; ${ }^{*} \mathrm{P}<0.05$ vs control; \# $\mathrm{P}<$ 0.05 vs $0.1 \mathrm{mM} ; \sim \mathrm{P}<0.05$ vs $1 \mathrm{mM}, \sim \mathrm{P}<0.05$ vs $5 \mathrm{mM}$ 


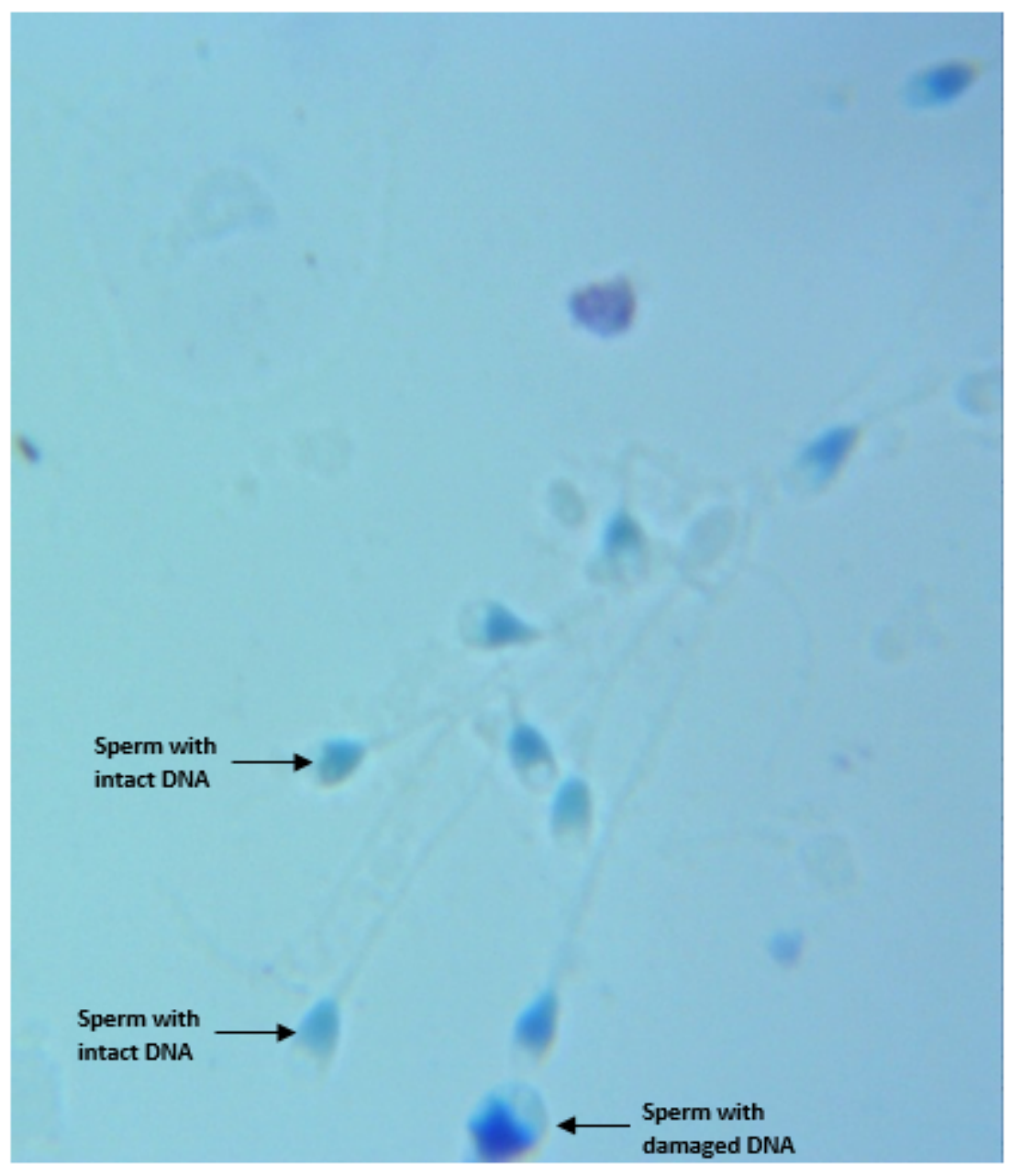

\section{Figure 3}

Representative photomicrograph of human spermatozoa showing those with intact and damaged DNA using Toluidine blue stain. 

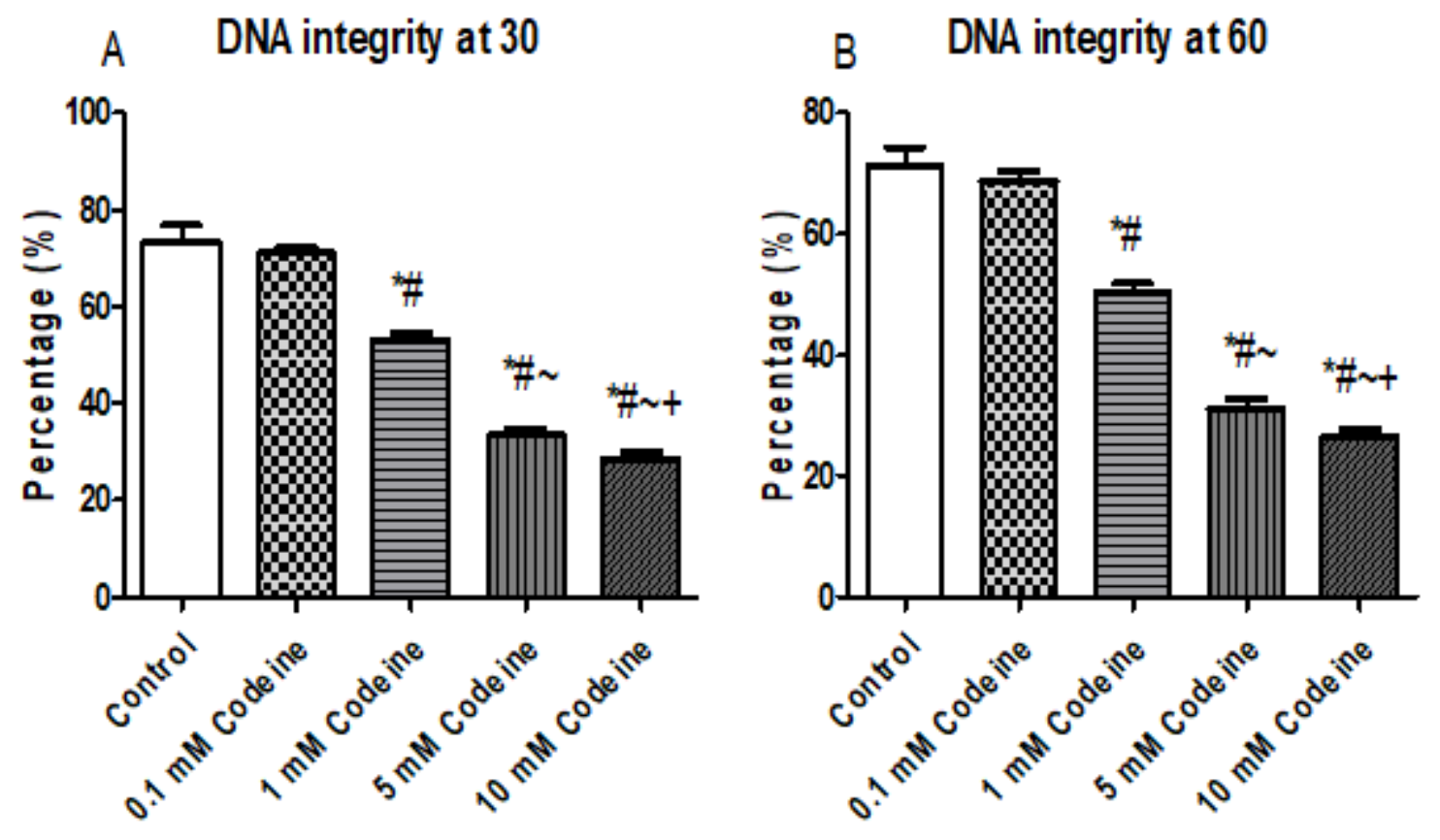

C DNA integrity at 90

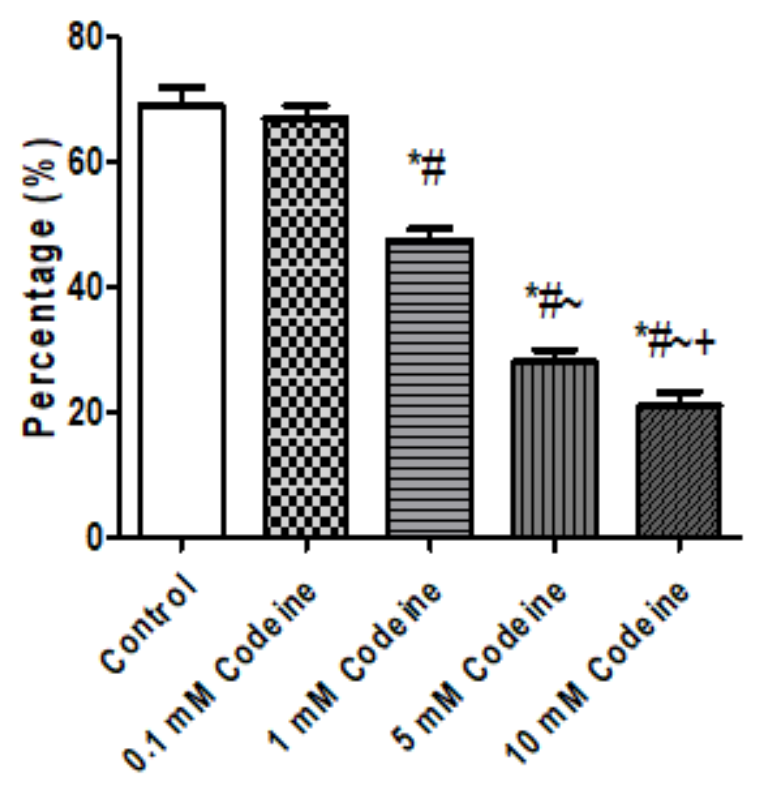

Figure 4

The effect of in vitro exposure to codeine on human sperm DNA integrity Data are presented as mean \pm SD of 5 replicates; ${ }^{*} \mathrm{P}<0.05$ vs control; \# $\mathrm{P}<0.05$ vs $0.1 \mathrm{mM} ; \sim \mathrm{P}<0.05$ vs $1 \mathrm{mM}, \sim \mathrm{P}<0.05$ vs $5 \mathrm{mM}$ 


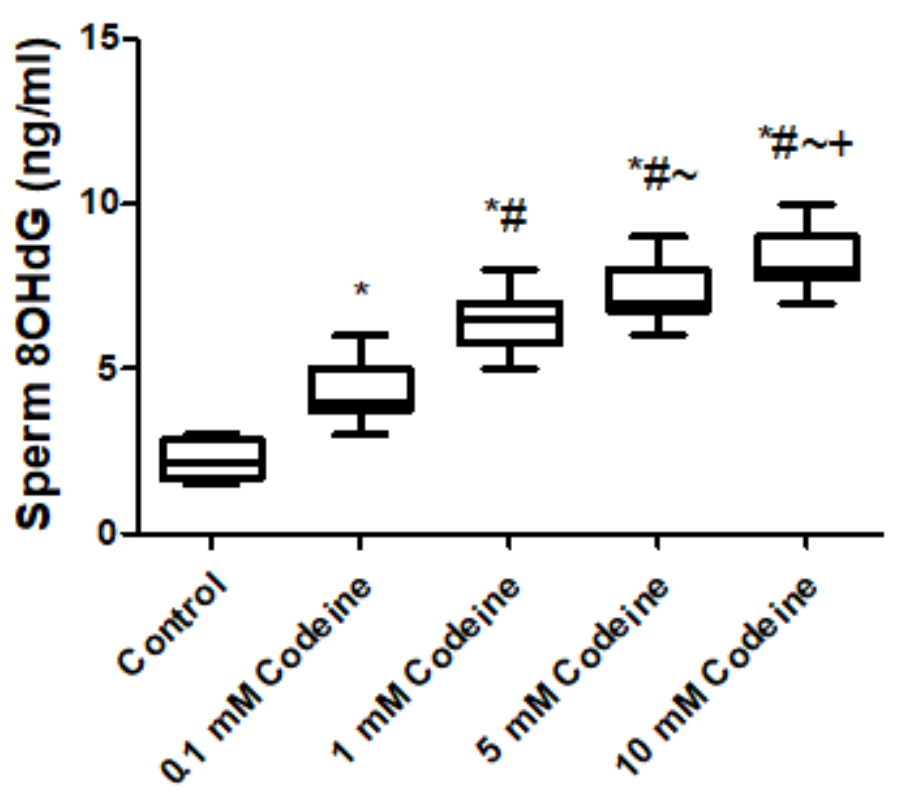

Figure 5

The effect of in vitro exposure to codeine on human sperm $80 \mathrm{HdG}$ Data are presented as mean \pm SD of 5 replicates; ${ }^{*} \mathrm{P}<0.05$ vs control; \# $\mathrm{P}<0.05$ vs $0.1 \mathrm{mM} ; \sim \mathrm{P}<0.05$ vs $1 \mathrm{mM}, \sim \mathrm{P}<0.05$ vs $5 \mathrm{mM}$
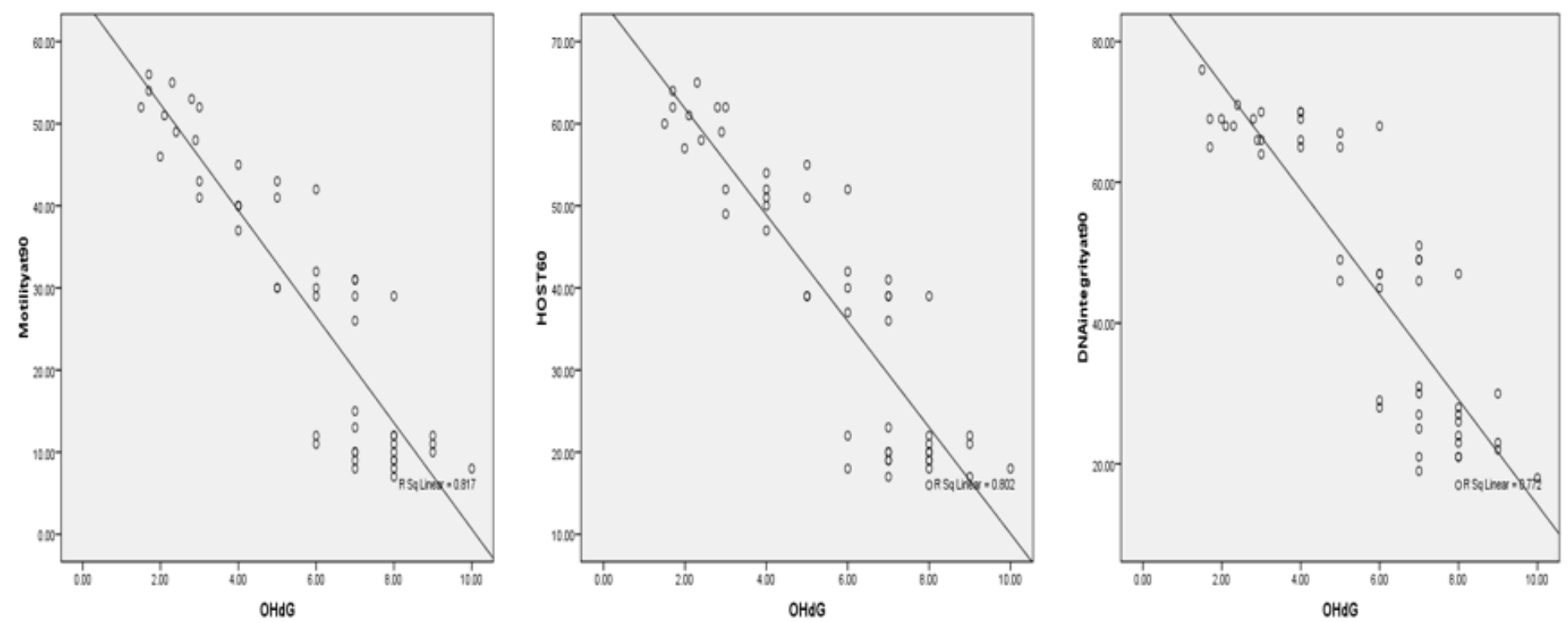

Figure 6

Correlation analysis showing the relationship between sperm $80 \mathrm{HdG}$ and sperm motility, plasma membrane integrity and DNA integrity 


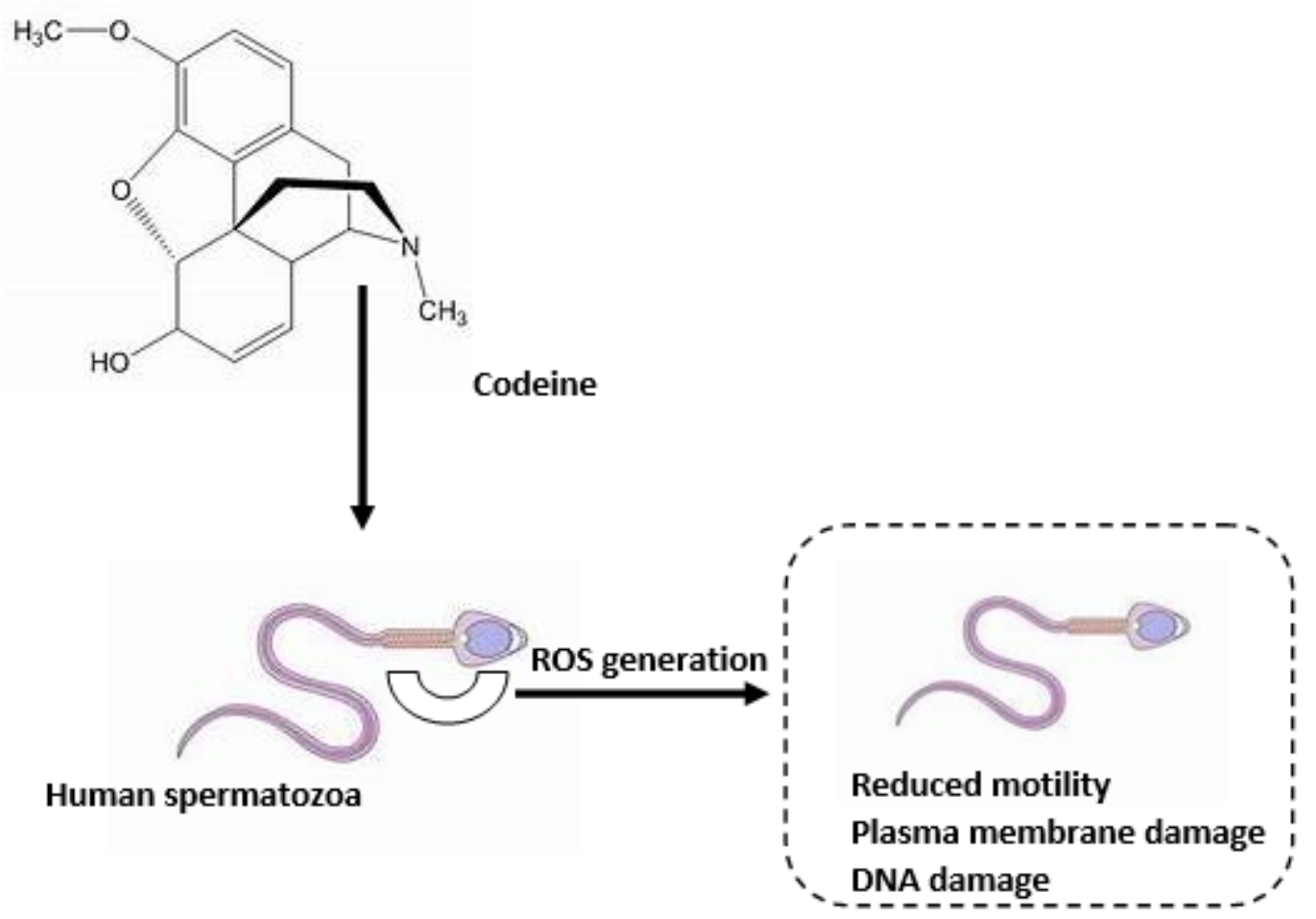

Figure 7

Graphical illustration of the impact and associated mechanism of codeine on human spermatozoa

\section{Supplementary Files}

This is a list of supplementary files associated with this preprint. Click to download.

- Graphicalabstract.docx 